\title{
ANÁLISE LINGUÍSTICA A PARTIR DE GÊNEROS NO LIVRO DIDÁTICO DE LÍNGUA PORTUGUESA: UMA VISÃO CONTRASTIVA
}

\author{
Karla Simões de Andrade Lima BERTOTTI ${ }^{1}$ \\ Renata Monteiro MENDES ${ }^{2}$
}

\begin{abstract}
Resumo: Este trabalho investiga como a análise linguística é trabalhada no livro didático de língua portuguesa a partir dos gêneros textuais. Este estudo fundamentou-se nas questões de análise linguística; na concepção dialógica da linguagem, e na abordagem do interacionismo sócio-discursivo, os quais defendem a ação dialógica da linguagem. Para análise, foram utilizadas duas coleções de livros didáticos. Como procedimento investigativo, fizemos apresentação da estrutura dos livros didáticos escolhidos e o levantamento quantitativo e qualitativo dos gêneros abordados na obra no que se refere às atividades de análise linguística. Os resultados revelaram que a prática de ensino por meio do trabalho com gêneros textuais, portanto, fornece aos alunos os conhecimentos linguísticos e textuais necessários para atuar reflexivamente em diferentes atividades comunicativas.
\end{abstract}

Palavras-chave: Análise linguística. Gênero textual. Livro didático.

\begin{abstract}
This paper investigates how the linguistic analysis is worked on in the Portuguese language coursebook from the textual genres. This study was based on questions of linguistic analysis; in the dialogical conception of language, and in the approach of socio-discursive interactionism, which defends the dialogical action of language. For analysis, two collections of coursebooks were used. As an investigative procedure, we presented the structure of the chosen coursebooks and the quantitative and qualitative survey of the genres regarding the linguistic analysis activities. The results revealed that the practice of teaching through work with textual genres, therefore, provides students with the linguistic and textual knowledge necessary to act reflexively in different communicative activities.
\end{abstract}

Keywords: Linguistic Analysis. Text Genre. Coursebook.

\section{Introdução}

Os Parâmetros Curriculares Nacionais (BRASIL, 1998), doravante PCN, documento formulado pelo Governo federal, apresentam uma proposta curricular educacional norteadora do trabalho docente que deveria ser seguido pelo professor no seu trabalho pedagógico.

Os PCN têm sido recorrentemente o tema de discussões sobre as práticas de ensino e aprendizagem por diversos educadores e pesquisadores que se preocupam com a situação da educação no Brasil. Enfatizando-se o ensino e a aprendizagem que estão centrados na teoria dos gêneros textuais tal como descritos nos PCN de Língua Portuguesa do Ensino Fundamental, e como estes são abordados pelos Livros Didáticos (doravante LD) destinados tanto às escolas públicas, como às particulares.

Os PCN de Língua Portuguesa tentam traduzir os avanços de pesquisa acumulados nas últimas décadas do século XX, nomeadamente as discussões introduzidas na academia, desde a entrada da Linguística no currículo dos cursos de Letras (em 1962) e do surgimento da Pós-graduação na área de Linguagem no país (décadas de 80 e 90).

Em sua produção, os PCN mobilizaram diversos especialistas e a década de noventa assistiu a um grande debate sobre reforma curricular, tanto na esfera acadêmica quanto na esfera governamental. No contexto dessa reforma, outra política que nos interessa destacar é o

\footnotetext{
${ }^{1}$ Doutoranda do Programa de Pós-graduação em Ciências da Linguagem da UNICAP, bolsista da CAPES, sob orientação do prof. Dr. Benedito Gomes Bezerra. karla.bertotti@ hotmail.com

${ }^{2}$ Doutoranda do Programa de Pós-graduação em Ciências da Linguagem da UNICAP, sob orientação da profa. Dra. Isabela do Rêgo Barros. renata.momendes@gmail.com
} 
Programa Nacional do Livro Didático (doravante PNLD), herdeiro de políticas de avaliação anteriores, compra e distribuição de LD no país, o PNLD passa a ser referência inclusive na produção do LD, pois o maior comprador do mercado editorial brasileiro, o Governo Federal, passa a lançar editais que regularão uma fatia significativa da comercialização de LD.

Nesse contexto, este trabalho busca analisar duas coleções de livros didáticos pertencentes ao catálogo de uma mesma editora, comparando suas abordagens teóricometodológicas no que diz respeito ao tratamento dado à analise linguística a partir da dos gêneros textuais trabalhados em cada LD.

A partir disso, fizemos um recorte temático para o trabalho, debruçamo-nos sobre nosso corpus com as seguintes questões: Como é trabalhada a questão dos gêneros textuais nas duas coleções? O foco é o mesmo? A análise linguística é abordada de que forma? A gramática interage com o gênero trabalhado ou é apresentada de forma descontextualizada?

Nos limites dessa abordagem, o objetivo geral deste trabalho é compreender como é realizada a análise linguística, proposta por cada $\mathrm{LD}$, a partir das teorias dos gêneros textuais e das orientações dadas pelos PCN através dos Livros Didáticos de Língua Portuguesa (doravante LDLP), como fator de vinculação escolar com as práticas sociais. Como objetivos decorrentes desse, elegemos como específicos: expor a discussão acerca dos gêneros textuais e suas implicações para o ensino de língua materna, através da bibliografia de referência; investigar o tratamento dado à análise linguística a partir dos gêneros textuais nas duas coleções selecionadas; e, por fim, identificar a proposta de cada coleção ao trabalhar o mesmo gênero textual em seu LD.

\section{Gêneros textuais e ensino da língua portuguesa}

A sociedade moderna exige uma escola dinâmica e estreitamente relacionada às funções sociais, a fim de que os alunos dominem as diversas práticas discursivas presentes no mundo contemporâneo. Desse modo, a escola passa a direcionar suas atividades, para a construção do conhecimento e das competências do educando formando um cidadão atuante que atende às demandas da nova sociedade vigente.

A escola, muitas vezes, se afasta da função de formar sujeitos aptos para intervir criticamente na realidade, tornando-se pouco interessante para o aluno. Além disso, por conta da exacerbação de métodos tradicionais, ela acaba dando importância ao que nem sempre é relevante para a aprendizagem do aluno, transmitindo, muitas vezes, conhecimentos de forma enfadonha, levando mais em conta a memorização do que o raciocínio e a criatividade.

A escola é utilizada muito mais para fazer comunicados do que para fazer comunicação e este papel é desempenhado tanto mais eficazmente, quanto mais o que se pretende com a ação escolar é formar o espírito ilustrado, não o espírito criador. Cedo ela se transforma numa instituição ritualista, onde o cumprimento de certas formalidades legais tem valor em si mesmo (ROMANELLI, 1978, p.23).

Como a prática pedagógica deve ser contextualizada, não é possível formular receitas prontas para serem aplicadas a qualquer grupo de alunos. O professor, diante de cada situação, precisará refletir, encontrar suas próprias soluções e tomar decisões relativas ao encaminhamento mais adequado, isto é, trabalhar, em sala, com as expectativas dos alunos.

A prática do professor reflete sua leitura de mundo. Afinal, somente um crítico forma outro crítico. De acordo com Silva (2002):

Não se pode culpar o professor, mas tentar, junto com este, modificar esta situação que provavelmente está relacionada com seu próprio processo de aprendizagem, investigando-a com o intuito de possibilitar novas perspectivas na prática pedagógica (SILVA, 2002, p. 236). 
Desta forma, o professor deve realizar a sua leitura de mundo, isto é, uma leitura da realidade vivida, e convidar os alunos a vivenciar com ele esta nova situação, levando o aprendiz a participar ativamente da sua aprendizagem. As relações de troca entre professor e alunos possibilitarão a construção do mundo da leitura.

O ser humano é eternamente mutável e, por isso, está em constante evolução, nos níveis biológico, social, mental, psicológico e espiritual. Ao olhar a história, é possível perceber-se o esforço do homem no sentido de se comunicar através das mais variadas linguagens existentes, na tentativa de acompanhar a mutação inerente ao seu ser, que leva a essa evolução (SILVA, 2002, p. 236).

A educação, preocupada em também acompanhar essa evolução do ser, torna-se um sistema em constante transformação, pois é algo que provém do homem e destina-se a servilo. Portanto, é imprescindível que também seja mutável. Essa mutabilidade, necessária à sua evolução, é um dos fatores que desencadeiam e alimentam o surgimento das várias propostas pedagógicas do sistema educacional.

Um dos documentos oficiais que atualmente regem o sistema educacional brasileiro é os Parâmetros Curriculares Nacionais - PCN (BRASIL,1998), produzido pelo governo federal para orientar os trabalhos dos ensinos fundamental e médio. Um outro, o Programa Nacional do Livro didático - PNLD (BRASIL, 2008), seleciona e encaminha os livros didáticos a serem utilizados nas escolas. Assentado, basicamente, nos pressupostos teóricos interacionistas desses dois documentos, o ensino de língua materna também vem procurando se adequar numa tentativa de acompanhar todo esse processo evolutivo.

$\mathrm{Na}$ busca de contribuir com a construção desse cidadão crítico, é que aparece, na escola, o livro didático, como um recurso auxiliar - muitas vezes único - destinado a colaborar com a tarefa do professor, figura imprescindível no processo de ensino e aprendizagem. Os PCN recomendam que os livros didáticos de Língua Portuguesa contemplem uma grande diversidade de gêneros textuais, a fim de enriquecer e oferecer ao aluno as mais diversas experiências de leituras e vivências do mundo. Por isso, a preocupação dos autores desses livros em inserir variados gêneros textuais em suas produções tem aumentado consideravelmente.

A referência a gêneros textuais remete diretamente a textos orais ou escritos concretizados em eventos comunicativos, estabelecendo as diferentes práticas discursivas que fazem parte de nossa vida nos diferentes âmbitos sociais a que estamos inseridos.

Desse modo, remete-se a Bakhtin, que aponta os gêneros textuais como componentes culturais e históricos, configurações repetitivas e expressivas de interagir em conjunto, que ordenam e estabilizam nossas relações na sociedade. Bakhtin (1992), ao tratar dos três fatores constituintes do enunciado, conteúdo temático, construção composicional e estilo do enunciado, menciona o querer dizer do locutor e destaca os gêneros do discurso, como a unidade da interação verbal. Para esse autor, o querer dizer de cada locutor se estabelece, principalmente, pela escolha de um gênero do discurso.

Esta escolha é determinada em função da especificidade de um dado campo discursivo definido em função do tema e dos parceiros da interação. Segundo Bakhtin (1992), para a efetiva comunicação, utilizamo-nos sempre dos gêneros do discurso. Em outras palavras, todos os nossos enunciados dispõem de uma forma padrão, através de gêneros do discurso tanto oral como escrito. Na prática, usamo-los com segurança e destreza, embora possamos ignorar sua existência teórica.

Para Koch (2002), é através da competência discursiva que os falantes/ouvintes identificam o que é adequado ou inadequado em cada uma de suas práticas sociais. Para a 
autora é essa competência que permite ao falante a escolha de determinados gêneros de textos, mesmo de forma inconsciente, como de estratégias de construção e interpretação de um texto. Dessa forma, os gêneros textuais podem ser considerados artefatos que viabilizam as várias práticas sociais de uso da linguagem, articulados de tal forma que são necessários à vida em sociedade. Os gêneros são, portanto, a efetiva realização da linguagem oral ou escrita.

Segundo Bazerman (2005), todo sujeito, através da comunicação por gêneros textuais, aprende mais sobre suas possibilidades pessoais, desenvolvendo habilidades comunicativas e compreendendo melhor o mundo com o qual está se comunicando. Assim, cada pessoa se torna apta a participar ativamente dentro dos espaços discursivos em que se inserem, comunicando e compreendendo melhor as situações comunicativas.

Segundo Bronckart (1999), os conhecimentos construídos sobre os gêneros estão sempre correlacionados às representações que temos sobre as situações sociais diversas em que atuamos. Desta forma, o conhecimento sobre o funcionamento da linguagem em diferentes situações de comunicação é o que possibilita aos aprendizes o entendimento do texto como construção social, adquirindo legitimação na relação entre texto e contexto de produção e distribuição.

A língua, sob o ponto de vista de sua efetivação, reflete, por meio dos gêneros (evento sociocomunicativo), os padrões de cultura e interação da comunidade em se que está inserida (BONINI, 2001). Em outras palavras, os gêneros refletem as inúmeras atividades sociais que estão no mundo. Quando conhecemos um gênero, conhecemos uma forma de realizar, linguisticamente, objetivos específicos em situações particulares (MARCUSCHI, 2002). Consequentemente, o conhecimento em termos de saber utilizar os diferentes gêneros textuais é uma ferramenta imprescindível de socialização para a inserção dos indivíduos nas práticas sociais, tendo a escola um papel importante nesse processo.

Bronckart (1999) destaca que a apropriação dos gêneros é um processo fundamental de socialização para a inclusão funcional dos indivíduos nas atividades comunicativas, uma vez que é através desse processo de apropriação que os indivíduos se tornam capazes de refletirem e agirem produtivamente e positivamente na sociedade.

Marcuschi, a exemplo de Bakhtin (1992), define os gêneros textuais como formas de ação social incontornáveis em qualquer situação comunicativa. Para este autor, "Gêneros textuais são formas verbais de ação social relativamente estáveis realizadas em textos situados em comunidades de práticas sociais e em domínios discursivos específicos" (MARCUSCHI,2002, p. 25).

Tal como foi posta a concepção de gêneros textuais por esses teóricos, os gêneros se constituem como ferramentas que permitem e tornam possível a compreensão dos processos de produção comunicativa, que se estabelecem dentro da sociedade.

Com base nessas questões, como também na proposta de ensino e aprendizagem sob a visão da teoria dos gêneros textuais incorporada aos PCN's, a prática de ensino de Língua Portuguesa por meio dos gêneros textuais se mostra uma importante ferramenta para a construção de conhecimentos relativos às manifestações reais da linguagem em nossas relações nas atividades sociais.

É nesse sentido que os PCN de Língua Portuguesa do ensino fundamental reiteram a função da escola de promover condições para que os alunos reflitam sobre os conhecimentos linguísticos construídos acerca dos gêneros ao longo de seu processo de socialização e possam agir sobre (e com) eles, transformando-os, continuamente, nas suas ações, conforme as demandas trazidas pelos espaços sociais em que atuam (PCN-EF, 1998), implicando formar o leitor e o produtor de texto.

A Pesquisa documental foi o nosso viés da coleta dos nossos dados, debruçando-nos em duas coleções escolhidas de forma aleatória destinadas ao mesmo ciclo e também de uma 
mesma editora, articulando a análise que faremos dos LD à proposta específica de cada autor, quanto ao trabalho da análise linguística a partir dos gêneros textuais em suas obras.

\section{Constituição do corpus}

Para esta análise foram selecionadas duas coleções de uma mesma editora, a primeira - fora selecionada pelo PNLD 2008 - Português - uma proposta para o letramento de Magda Soares. $6^{\circ}$ ao $9^{\circ}$ ano - editora Moderna e a segunda coleção - não consta na lista dos livros aprovados pelo PNLD 2008 - Português: leitura, produção, gramática de Leila Lauar sarmento. $6^{\circ}$ ao $9^{\circ}$ ano - editora Moderna.

Com o propósito de atingir o objetivo desta pesquisa, que é compreender como é realizada a análise linguística a partir do uso das teorias dos gêneros textuais e das orientações dadas pelos PCN - fatos discutidos na Seção 1 deste artigo - através dos livros didáticos de Língua Portuguesa do Ensino Fundamental, como fator de vinculação escolar com as práticas sociais.

Um dos objetivos dos Parâmetros Curriculares de Língua Portuguesa do ensino fundamental é trabalhar o conhecimento necessário sobre as diferentes formas de realização da linguagem na sociedade, a fim de que o sujeito envolvido no processo de aprendizagem possa se comunicar produtivamente nos grupos sociais de que participa. Por isso, sugere-se aos professores que ensinem seus alunos a utilizar-se da linguagem na escuta e produção de textos orais e na leitura e produção de textos escritos de modo a atender as múltiplas demandas sociais, responder a diferentes propósitos comunicativos e expressivos, e considerar as diferentes condições de produção do discurso (PCN-EF, 1999).

No encaminhamento desses critérios, seguiremos os seguintes aspectos:

- Como se baseia a estrutura do LD analisado;

- Qual o direcionamento metodológico dado ensino e aprendizagem de língua materna a partir dos Gêneros Textuais;

- A formulação e intencionalidade de cada autor ao trabalhar o mesmo gênero textual em seu LD.

\section{Visão geral das coleções}

\subsection{Coleção 1}

Português - uma proposta para o letramento de Magda Soares é uma coleção constituída de quatro volumes destinada aos alunos do $6^{\circ}$ ao $9^{\circ}$ ano do $\mathrm{EF}$, a divisão dos capítulos de cada volume mostra os princípios norteadores da coleção, além de apresentar toda a estrutura do LD e sua bibliografia.

A coleção 1 divide cada livro em 4 capítulos e esses capítulos rodam e trabalham o mesmo tema, embora trabalhe com diversos gêneros, como podemos verificar, no mesmo capítulo ela pode tanto iniciar com um poema, ou mesmo outro gênero, partindo para notícia, reportagem, crônica, reportagem, conto entre outros e sempre se preocupando em trazer a funcionalidade do gênero além de trabalhá-lo enquanto texto escrito ou oral.

Percebemos claramente ao manusear essa coleção seus objetivos quanto ao ensino de língua materna, fundamentando-se sempre nas concepções do Letramento, criando situações em que o aluno tenha oportunidade de refletir sobre textos que se remetem a situações do dia a dia, desenvolvendo habilidades de interação social através da dos gêneros que sua coleção aborda. 


\subsection{Coleção 2}

Português: leitura, Produção, Gramática de Leila Lauar Sarmento é uma coleção constituída de quatro volumes destinada aos alunos do $6^{\circ}$ ao $9^{\circ}$ ano do Ensino Fundamental. Cada LD é formado por quatro unidades temáticas compostas por dois capítulos.

$\mathrm{Na}$ Coleção 2, cada unidade é iniciada sempre com um texto visual, normalmente uma obra artística, e logo em seguida a autora trabalha em cada capítulo dois ou até mesmo três textos, mudando o gênero textual de uma unidade para outra. O trabalho voltado à parte gramatical e à produção textual estão identificadas por meio seções especificadas, o que deixa claro quando termina uma parte e quando começa a outra.

Salta aos olhos a diversidade de gêneros selecionados pela autora para sua proposta didática. Percebe-se que o trabalho de compreensão textual é bastante numeroso, porém é feito inúmeras vezes como decodificação ou de cópia, compreender seria uma extração de conteúdos.

Em alguns casos ainda a compreensão de um gênero mistura-se com outros mostrando que não há uma uniformidade, como também percebemos exercícios genéricos que podem ser respondidos sem necessariamente estarem acoplados ao texto exposto, como explica Marcuschi, "Perguntas Vale-tudo: Indagam sobre questões que admitem qualquer resposta não havendo possibilidade de se equivocar. A ligação com o texto é apenas um pretexto sem base alguma para a resposta" (Marcuschi, 2001,p.53).

\section{Universo da pesquisa}

A fim de melhor exemplificar a pesquisa realizada, resolvemos fazer um recorte do material selecionado, no intuito de ilustrar de forma mais eficaz nosso objetivo. Escolhemos da coleção mencionada o $4^{\circ}$ Ciclo, por ser o último do Ensino Fundamental e deste, o $9^{\circ}$ ano por ser o ano de transição entre o Ensino Fundamental e o Médio.

Através da análise dos livros, pode-se perceber as teorias que norteiam o trabalho do professor e as concepções de linguagem e ensino de língua que estão sendo a base das aulas de língua portuguesa. Isso porque o LD ganhou espaço nas salas de aula e hoje cabe a ele um papel que anteriormente cabia ao professor.

De auxiliador, o livro passou a ser o principal recurso utilizado em sala de aula. Acredita-se que essa realidade não tende a mudar nos próximos anos, Por isso é tão importante repensar e entender a atitude e a prática do professor hoje em sala de aula. Sua identidade está cada vez mais exposta e a sociedade cobra, um docente atualizado e apropriado às exigências atuais.

Os PCN estão nas escolas e à disposição dos docentes desde os anos noventa, mas somente agora tanto os professores como os livros didáticos tentam trabalhar de forma contextualizada.

A partir da preocupação com a contextualização que hoje encontramos nos LD, fez-se necessário partir para uma nova realidade nos LDLP. Desta feita, passaram a incorporar em seu acervo textual diversos gêneros a serem trabalhados na escola com o intuito de trazer a realidade e os diversos textos que circulam na sociedade. Segundo Marchuschi(2008), "a vivência cultural humana está sempre envolta em linguagem, e todos os nossos textos situamse nessas vivências estabilizadas em gêneros" (p.163).

\section{Livros didáticos analisados}




\subsection{Livro didático 1}

O quarto volume da coleção Português - Uma proposta para o Letramento Gramática de Magda Soares destinada ao nono ano do Ensino Fundamental divide-se em quatro unidades temáticas ( $1^{\mathrm{a}} \mathrm{UD}$ - tema: Somos Sós no Universo, $2^{\mathrm{a}} \mathrm{UD}$ - tema: Tempo Você, $3^{\text {a }}$ UD - tema: O Homem Lobo do Homem, $4^{\text {a }}$ UD - tema: A Língua que Eu Falo), derivando dessas unidades um conjunto de cinco ou mais subunidades, apoiadas por gêneros e tipos textuais. Os textos apresentados em cada unidade estruturam-se num eixo de leitura, produção de texto, linguagem oral e reflexões sobre a língua portuguesa.

Os textos literários, jornalísticos e publicitários são trabalhados de forma abrangente pela autora. Percebe-se uma preocupação específica quanto ao trabalho com os gêneros textuais, buscando através das atividades propostas, estabelecer diferentes estratégias cognitivas, a fim de que o aluno consiga apropriar-se das características dos gêneros e dos tipos textuais, reconhecendo sua finalidade.

A proposta de desenvolvimento de usos da língua está ancorada num trabalho consistente de reflexão e de construção de conhecimentos sobre a língua. A abordagem da leitura, dos conhecimentos linguísticos e da produção de textos é realizada de maneira articulada e equilibrada, sem que se privilegie uma habilidade em detrimento das outras.

A seleção de textos contempla variedade de autores, de tipos e gêneros de texto, e é voltada para o desenvolvimento de habilidades de leitura, análise linguística e produção de diversificados gêneros e tipos textuais. A presença de textos com registros e variedades diferentes ressalta o caráter heterogêneo da língua. Há uma presença significativa de textos literários, que representam a maioria dos textos do volume. O contexto social também é bastante diversificado predominando textos da imprensa, literatura, ciência e música.

O volume apresenta uma temática única em cada unidade, a obra expõe os conteúdos de forma harmônica, deixando que o desenvolvimento do trabalho possa ser bem construído pelo docente. Os assuntos se misturam no intuito de trabalhar a língua como um todo, retirando aquele formato tradicional: texto, interpretação, gramática e produção. $\mathrm{O}$ ensino da gramática está sempre entrelaçada aos demais eixos.

Segundo o Guia de Livros Didáticos PNLD 2008, a obra de Magda Soares desenvolve como projeto pedagógico:

Trabalhar a língua como instrumento de interlocução, como prática social de interação, com propostas que contextualizam as atividades de ensino em situações de uso, com finalidades específicas, interlocutores reais e textos de circulação no meio social. A obra assume o letramento como finalidade principal do ensino da língua: o aluno deve não apenas saber ler e escrever, mas ser proficiente no uso social da língua, falando ou escrevendo. (Guia de Livros Didáticos PNLD 2008, p.70).

A reflexão sobre a língua está constantemente presente, quando a autora propõe o trabalho com os conhecimentos linguísticos, possibilitando uma compreensão das questões linguísticas nas devidas situações de oralidade e escrita, também com das variedades da língua. Para tanto, a autora trabalha com a parte teórica, porém sempre mostrando e abordando os aspectos semânticos, mas nunca com uma sistematização dos conteúdos seguidos pelos moldes da gramática tradicional. Os conhecimentos linguísticos trabalhados levam o discente a exercitar algumas de suas competências tais como a observação, a análise, a comparação a transformação e a produção.

\subsection{Livro didático 2}


O quarto volume da coleção Português - Leitura. Produção. Gramática de Leila Lauar Sarmento destinada ao nono ano do Ensino Fundamental divide-se em quatro Unidades temáticas e cada uma delas é dividida em dois capítulos, esses giram sempre em torno do tema central da Unidade ao qual pertencem; todas elas apresentam atividades de leitura, produção de texto e conhecimentos linguísticos.

A parte voltada para os conhecimentos linguísticos contempla o que tem sido considerado tradicionalmente como programa de $6^{\circ}$ ao $9^{\circ}$ ano do Ensino Fundamental no que se refere à descrição da língua (classe de palavras, termos da oração, estrutura do período composto, figuras de linguagem) e aos aspectos normativos (ortografia, regência , concordância, construções sintáticas).

Este volume está voltado para o desenvolvimento de habilidades de leitura, redação, assim como para a descrição gramatical do Português. Seus pressupostos teóricometodológicos baseiam-se em concepções tradicionais de língua, gramática e texto.

A sua seleção textual é bastante diversificada, a autora trabalha em sua obra diversos gêneros textuais, enfatizando alguns em detrimento de outros, percebemos ainda que alguns gêneros são meramente ilustrativos, aparecendo apenas para análise gramatical e não com sua função real.

Considerando-se a predominância de textos literários, constata-se ao longo do volume analisado que tais textos ora se restringem a atividades estruturais, de interpretação, ora apenas para estudo de conteúdos gramaticais.

Os conhecimentos linguísticos são abordados ao longo do volume analisado: aparecem nas partes Palavras e significados, Linguagem e Interação, fatos da língua e Gramática. Para essa abordagem, porém, a seção privilegiada é a de Gramática. Essa seção se baseia na tradição gramatical normativa e seus principais conteúdos são refrente à sintaxe - da oração, de concordância, de regência e de colocação. O trabalho realizado no volume tende a se mostrar adequada, embora se deva ressalvar a falta de articulação entre a exploração dos conhecimentos linguísticos e a leitura e a produção de textos, assim como o pouco incentivo dado à reflexão (a ênfase tende a recair nos exercícios de reconhecimento e memorização). A seção destinada a esses conhecimentos traz uma situação, explicitada num pequeno texto, em fragmentos, poemas, quadrinho ou peças publicitárias que serão fonte de apresentação do conteúdo teórico a ser trabalhado. O trabalho se orienta a partir da exposição e memorização da nomenclatura de definições e classificações.

Constata-se uma desarticulação entre o que se procura ensinar de gramática e as atividades de leitura e escrita devido à descontextualização desse trabalho e ao grau de abstração com que são tratadas em relação ao conhecimento linguístico do aluno e ao uso efetivo da língua.

\section{Considerações finais}

Sob a visão da teoria dos gêneros textuais incorporada aos PCN, a prática de ensino de Língua Portuguesa por meio dos gêneros textuais se mostra uma importante ferramenta para a construção de conhecimentos relativos às manifestações reais da linguagem em nossas relações nas atividades sociais.

É nesse sentido que os PCN de Língua Portuguesa do Ensino Fundamental reiteram a função da escola de promover condições para que os alunos reflitam sobre conhecimentos linguísticos construídos acerca dos gêneros ao longo de seu processo de socialização e possam agir sobre (e com) eles, transformando-os, continuamente, nas suas ações, conforme as demandas trazidas pelos espaços sociais em que atuam. 
Esta pesquisa possibilitou identificar como é feito o trabalho com os gêneros textuais nos livros didáticos para o ensino de Língua Portuguesa como uma referência que pode passar a formar parte da "base de conhecimento" para o trabalho do (a) professor(a) como profissional ao ensinar as questões relacionadas à língua portuguesa, principalmente no tocante aos conhecimentos linguísticos. Não se propõe uma "receita" para analisar os livros, e sim uma referência a mais dentre outras.

Convém destacar não ter sido objeto de nossa investigação o livro didático como um todo, mas sim a abordagem dada por ele no que tange ao ensino da análise linguística através dos gêneros textuais e que efeito essa abordagem produziria na prática social do aluno.

Como procedimento de análise identificamos que o LD1 propõe-se a trabalhar com um número reduzido de gêneros - referindo-se a ocorrências encontradas-, diferentemente do LD2, cuja proposta apresenta uma ocorrência de um maior número de gêneros. Vale salientar que não se defende aqui que um não é melhor que o outro em função do número de ocorrências, mas sim apresentam propostas diferentes de trabalho.

Identificamos as seções que abordavam os gêneros e conseguimos verificar claramente a distinção de trabalho entre os dois LD, a partir da descrição de como cada LD está estruturado, baseando-se nos no eixo destinado aos conhecimentos linguísticos.

Desta forma, levando-se em consideração o uso de gêneros textuais, como ferramentas norteadoras de ensino e aprendizagem de Língua Portuguesa, possibilitará aos professores levar para a sala de aula não só atividades gramaticais com a língua e a linguagem por si mesmas, mas como meios de mostrar as diferentes práticas sociais.

Quanto maior for a vivência dessas práticas comunicativas na sala de aula maior será a capacidade do aluno de refletir sobre suas produções textuais em contextos reais de comunicação e, consequentemente, sobre valores ideológicos que as perpassam, o que também contribui, de forma eficaz, tanto para a capacitação dos professores de Língua Portuguesa como para a melhoria do Ensino Fundamental, e, portanto, para o aperfeiçoamento do exercício da cidadania dos sujeitos além do contexto escolar.

\section{Referências}

ANTUNES, I. C.. Muito além da gramática: Por um ensino sem pedras no caminho. $1^{\text {a }}$ Edição. Belo Horizonte: Ed. Parábola, 2007.

BAGNO, M. Sete erros aos quatro ventos: a variação linguística no ensino de português. São Paulo: Parábola Editorial, 2013.

BAKHTIN, M. Estética da Criação Verbal. 2. ed. São Paulo:Martins Fontes, 1992.

BAZERMAN, C. Gêneros textuais, tipificação e interação. São Paulo: Cortez, 2005.

BONINI, A. Ensino de gêneros textuais: a questão das escolhas teóricas e metodológicas. (Trabalhos em Linguística Aplicada, 2001).

BRASIL, Ministério da Educação. Guia de livros didáticos PNLD: Língua Portuguesa.Ministério da educação. Brasília: MEC, 2008.

BRASIL, Ministério da Educação. Parâmetros Curriculares Nacionais - Ensino fundamental- Língua Portuguesa. Brasília: MEC, 1998. 
BRONCKART, J. P. Atividade de linguagem, textos e discursos: Por um interacionismo sócio-discursivo. São Paulo: EDUC, 1999.

FÁVERO, L.L., KOCH, I, G, V. Linguística textual : introdução. São Paulo: Cortez, 2012.

GERALDI, J. Portos de Passagem. 4ed. São Paulo: Martins Fontes, 2003.

MARCUSCHI, L. A. . Da fala para a escrita: atividades de retextualização. 3..ed. São Paulo, Cortez: 2001.

. Gêneros textuais: e funcionalidade. In: DIONÍSIO, A. P.,MACHADO, A. R. e BEZERRA, M. A. (orgs). Gêneros textuais e ensino. Rio de Janeiro: Lucerna, 2002.

A produção textual, análise de gêneros e compreensão. 3.ed.. São Paulo: Parábola Editoria, 2008.

NEVES, M. H. de M. A gramática-história, teoria, análise e ensino. São Paulo. UNESP, 2002.

ROMANELLI, O. História da Educação no Brasil: 1930-1973. Petrópolis-RJ: Vozes, 1978.

SARMENTO, L. L.. Português: leitura, produção, gramática $/ 6^{\circ}$ ao $9^{\circ}$ ano. 3ed. São Paulo: Moderna, 2009.

SCHENEUWLY, B; DOLZ, J. Gêneros orais e escritos na escola. Trad. e org. Roxane Rojo e Gláis Sales Cordeiro. Campinas, São Paulo: Mercado das Letras, 2004.

SILVA, R. R. N. e. Professor Leitor e o Processo de Ensino In: G.L. Guimarães e T. Leal (Orgs.) Formação de Professores. Recife-PE: Bagaço, 2002.

SOARES, M. Português: uma proposta para o letramento/ $6^{\circ}$ ao $9^{\circ}$ ano. 1ed. São Paulo: Moderna, 2002.

SUASSUNA, L. Ensino de língua portuguesa: uma abordagem pragmática. Campinas, SP: Papirus, 1995. 